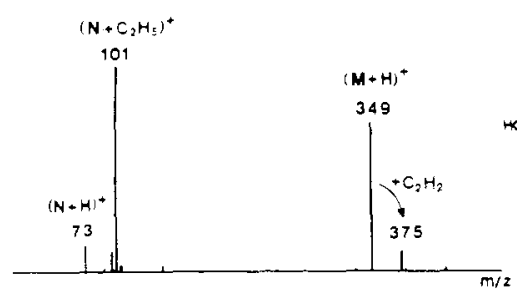

$0.5 \mathrm{ev}$
$2 \mathrm{mior}$

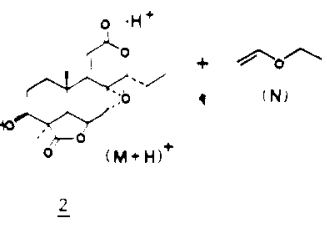

$\left(\mathbf{N}+\mathrm{C}_{5} \mathrm{H}_{5}\right)^{+}$
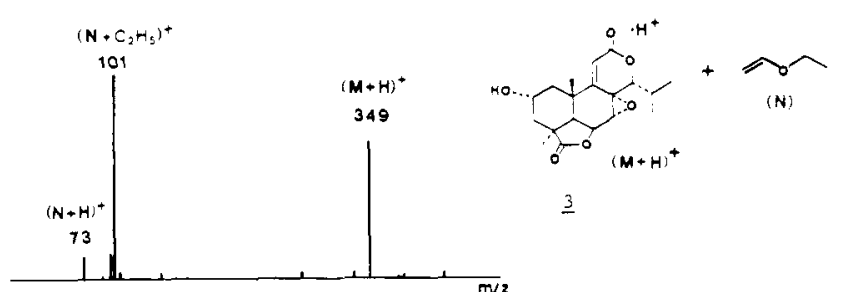

Figure 1. The product distributions obtained for two protonated, isomeric diterpenoid dilactones upon collisions with ethyl vinyl ether in the center quadrupole of a triple quadrupole mass spectrometer. The base peak $\left(\mathrm{NOl}^{+}\right)$arises from ethylation of ethyl vinyl ether by protonated ethyl vinyl ether $\left(73^{+}\right) .{ }^{5 c}$,

terium at a nonacidic site, as evidenced by the fact that this deuterium cannot be exchanged to a hydrogen atom upon collisions with ethyl vinyl ether. The large difference in the heat of formation of simple neutral alkyl vinyl ethers and alcohols $\left(\Delta\left(\Delta H_{\mathrm{f}}\right)\right.$ $=-22 \mathrm{kcal} / \mathrm{mol}$ for ethyl vinyl ether and ethanol) is the most likely driving force for this entropically disfavored reaction. We estimate the reaction to be at least $4 \mathrm{kcal} / \mathrm{mol}$ exothermic for protonated 4-hydroxy-2-butanone and ethyl vinyl ether. ${ }^{10}$ Note that the proton affinities of $\beta$-hydroxycarbonyl compounds are comparable to the proton affinities of alkyl vinyl ethers. ${ }^{10}$ This precludes efficient competition by the reaction that usually dominates the ion chemistry of alkyl vinyl ethers, i.e., deprotonation of the reactant ions.

The most intriguing result of this study is the discovery that "vinylation" of organic ions by alkyl vinyl ethers is highly selective toward different oxygen-containing functionalities and that this behavior is not limited to simple model ions but applies to complex polyfunctional ions as well. Under the same conditions, only dissociation and deprotonation reactions were observed for a number of protonated alcohols, ethers, aldehydes, ketones, esters, lactones, and epoxides, including mono- and polyfunctional, saturated and unsaturated, cyclic and acylic as well as aromatic molecules. To test the selectivity of the "vinylation" reaction more rigorously, we decided to examine the reactivity of polyfunctional molecules that only differ by the position of the hydroxy group expected to be necessary for the reaction. The isomeric diterpenoid dilactones $\mathbf{2}$ and 3 (Figure 1) present a challenging test since these protonated molecules are difficult to distinguish on the basis of their dissociation product distributions. However, due to steric constraints in the isomer $\mathbf{3}$, only $\mathbf{2}$ is expected to exchange a proton to a vinyl group upon collisions with ethyl vinyl ether. We found that protonated 2 does indeed undergo the reaction of interest, giving a product ion with a relative abundance of up to $10 \%$ of the base peak $\left(101^{+}\right)$, while 3 only gives a trace at the mass value of interest ( $\leq 1 \%$ of the base peak; Figure 1). Moreover, the reaction seems to be independent of the structure of the rest of the molecule. For the six diterpenoid dilactones (1-6) shown in

(10) $\Delta H_{\mathrm{f}}$ of protonated 4-hydroxy-2-butanone was estimated to be $\geq 62.9$ $\mathrm{kcal} / \mathrm{mol}$ by assuming that the proton affinity of 4-hydroxy-2-butanone is equal to or less that of acetyl acetone (i.e. $\leq 207.8 \pm 5 \mathrm{kcal} / \mathrm{mol}^{11}$ ), and estimating $\Delta H_{\mathrm{f}}$ for neutral 4 -hydroxy-2-butanone (estimated to be -95.4 $\mathrm{kcal} / \mathrm{mol}$ by the method of Benson ${ }^{12}$ and using $\Delta H_{\mathrm{f}}$ of 2-butanone: -57.5 $\mathrm{kcal} / \mathrm{mol}^{11}$ ); $\Delta H_{\mathrm{f}}$ of $\alpha$-deprotonated 4 -hydroxy-4-methylpyran was estimated to be $+80.9 \mathrm{kcal} / \mathrm{mol}$ by the method of Benson ${ }^{12}$ and using $\Delta H_{\mathrm{f}}=+129$ $\mathrm{kcal} / \mathrm{mol}$ for $\alpha$-deprotonated pyran: ${ }^{11} \Delta H_{\mathrm{f}}$ of ethyl vinyl ether is $-34 \mathrm{kcal} /$ $\mathrm{mol},{ }^{11} \Delta H_{\mathrm{f}}$ of ethanol is $-56.1 \mathrm{kcal} / \mathrm{mol}^{1}{ }^{1}$

(11) Lias, S. G.; Bartmess, J. E.; Liebman, J. F.; Holmes, J. L.; Levin, R. D.; Mallard, W. G. J. Phys. Chem. Ref. Data, Suppl. 1 1988, 17

(12) Benson, S. W. Thermochemical Kinetics; Wiley: New York, 1976.
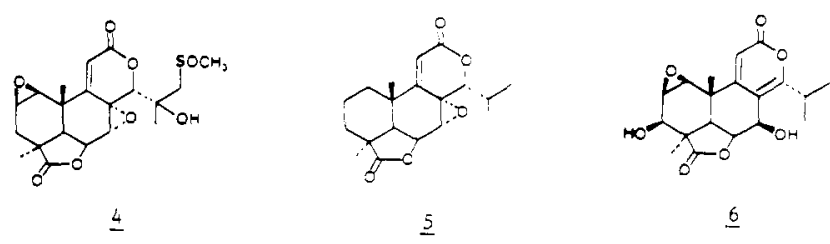

Scheme I, Figure 1, and below, the reaction is limited to those molecules $(\mathbf{1}, \mathbf{2}, \mathbf{6})$ that contain a 3 -hydroxy functionality in the A ring.

Acknowledgment. This work was supported by the National Science Foundation (CHE-8721768, RGC; CHE 8717380, HIK). Professor J. Cassady is acknowledged for samples of 1-6.

\section{A Double-Stranded DNA Fragment Shows a Significant Decrease in Double-Helix Stability After Binding of Monofunctional Platinum Amine Compounds}

Carla J, van Garderen, Hans van den Elst,

Jacques H. van Boom, and Jan Reedijk*

Department of Chemistry, Gorlaeus Laboratories Leiden University, P.O. Box 9502, 2300 RA Leiden The Netherlands

Leo P. A. van Houte

\section{Department of Biophysics, Physics Laboratory Free University, De Boelelaan 1081 $1081 \mathrm{HV}$ Amsterdam. The Netherlands Received January 17, 1989}

The antitumor drug cis-diamminedichloroplatinum(II) (cDDP ${ }^{1}$ ) preferentially binds to two neighboring guanine bases of DNA. ${ }^{2-4}$ It has been suggested that this chelation induces a serious distortion of the DNA, resulting in a denaturation up to several base pairs. ${ }^{5,6}$ Recently, NMR studies and molecular mechanics of oligonucleotides containing eight or more base pairs showed that the distortion is small; all base pairs, even those of the platinated guanines, are observed. ${ }^{7,8}$ Nevertheless, the melting temperature $\left(T_{\mathrm{m}}\right)$ appeared to be lowered by $10-20^{\circ} \mathrm{C}$. These phenomena have been attributed to a "kinked" cDDP-DNA structure., 9

For a detailed understanding of the working mechanism of cDDP not only the ultimate structural change but also the distortion resulting from the first binding step is important.

(1) Abbreviations: cDDP, ci. $-\mathrm{PtCl}_{2}\left(\mathrm{NH}_{3}\right)_{2}$; tDDP, trans- $\mathrm{PtCl}_{2}\left(\mathrm{NH}_{3}\right)_{2}$; dien, diethylenetriamine; dsNON A, d(TCTCGTCTC).d(GAGACGAGA); Pt(dien)-dsNONA, Pt(dien) [d(T(:TCGTCTC)-N7(5)] d(GAGACGAGA); $\mathrm{Pt}\left(\mathrm{NH}_{3}\right)_{3}$-dsNONA, Pt $\left(\mathrm{NH}_{3}\right)_{3}[\mathrm{a}$ 'TCTCGTCTC)- $\mathbf{N} 7(5)] \cdot \mathrm{d}(\mathrm{GAGACGA}-$ $\mathrm{GA}) ; T_{m}$, melting temperature.

(2) Fichtinger-Schepman, A. M. I,; van der Veer, J. L.; den Hartog, J. H. J.; Lohman, P. H. M.; Reedijk, J. biochemistry 1985, 24, 707-713.

(3) Inagaki, K.; Kidani, Y. Inorg. Chim. Acta 1985, 106, 187-191.

(4) Pinto, A. L.; Lippard, S. J. Biochim. Biophys. Acta 1985, 780 , $167-180$.

(5) Munchausen, L. L.; Rahn, R. O. Biochim. Biophys. Acta 1975, 414, 242-252.

(6) Macquet, J.-P.: Butour, J.-L. Biochimie 1978, 60, 901-914.

(7) den Hartog, J. H. J.; Altona, C.; van Boom, J. H. van der Marel, G. A.; Haasnoot, C. A. G.; Reedijk, J. J. Am. Chem. Soc. 1984, 106, 1528-1530.

(8) van Hemelryck, B.; Guittet, E.; Chottard, G.; Girault, J.-P.; HuynhDinh, T.; Lallemand, J.-Y.; Igolen, J.; Chottard, J.-C. J. Am. Chem. Soc. 1984, $106,3037-3039$.

(9) den Hartog, J. H. J.; Altona, C.; van Boom, J. H.; van der Marel, G. A.; Haasnoot, C. A. G.; Reedijk, J. J. Biomol. Struct. Dyn. 1985, 2, $1137-1185$

(10) Kozelka, J.; Archer, S.; Petsko. G. A.; Lippard, S. J.; Quigley, G. J. Biopolymers 1987, 26, 1245-1271. 
Table I. Melting Temperatures of Three Oligonucleotides Modified with cDDP and One Nonanucleotide Platinated with [Pt(dien) $]^{2+}$ or $\left[\mathrm{Pt}\left(\mathrm{NH}_{3}\right)_{3}\right]^{2+f}$

\begin{tabular}{|c|c|c|c|c|c|c|}
\hline oligonucleotide & duplex & added salt & $\begin{array}{c}T_{\mathrm{m}}(-\mathrm{Pt}) \\
\left({ }^{\circ} \mathrm{C}\right)\end{array}$ & $\begin{array}{c}T_{\mathrm{m}}(+\mathrm{P} 1) \\
\left({ }^{\circ} \mathrm{C}\right)\end{array}$ & $\begin{array}{l}T_{\mathrm{m}} \\
\left({ }^{\circ} \mathrm{C}\right)\end{array}$ & ref \\
\hline$d(G A T C C G G \bar{A}) \cdot d(G C C G G A T C G C)$ & $(\mathrm{Pt}-) \mathrm{A}^{a}$ & $1 \mathrm{M} \mathrm{NaCl}$ & 55 & 28 & 27 & 8 \\
\hline$d(G C C G G \overline{A T C G C}) \cdot d(G C G A T C C G G C)$ & $(\mathrm{Pt}-) \mathrm{B}^{b}$ & $1 \mathrm{M} \mathrm{VaCl}$ & 58 & 49 & 9 & 21 \\
\hline $\mathrm{d}(\mathrm{TCTCGGTCTC)} \cdot \mathrm{d}(\mathrm{GAGACCGAGA})$ & $(\mathrm{Pt}-) \mathrm{C}^{\mathrm{c}}$ & none & 29 & 14 & 15 & 7 \\
\hline $\mathrm{d}(\mathrm{TCTCGGTCTC}) \cdot \mathrm{d}(\mathrm{GAGACCGAGA})$ & $(\mathrm{Pt} \sim) \mathrm{C}^{d}$ & $0.1 \mathrm{M} \mathrm{Mg}^{2+}$ & 52 & 30 & 22 & 22 \\
\hline$d($ TCTCGTCTC) $\cdot d(G A G A C G A G A)$ & $e$ & $0.5 \mathrm{M} \mathrm{NaCl}$ & 42 & 26 & 16 & this work \\
\hline
\end{tabular}

${ }^{a} \mathrm{~A}, 23 \mu \mathrm{M} ; \mathrm{Pt}-\mathrm{A}, 8 \mu \mathrm{M} .{ }^{b} 1 \mu \mathrm{M} .{ }^{c} 5 \mu \mathrm{M}$. ${ }^{d} 6.4 \mu \mathrm{M}$. ${ }^{e} 4-5 \mu \mathrm{M}$. ${ }^{f}$ The platinated sequences are underlined.

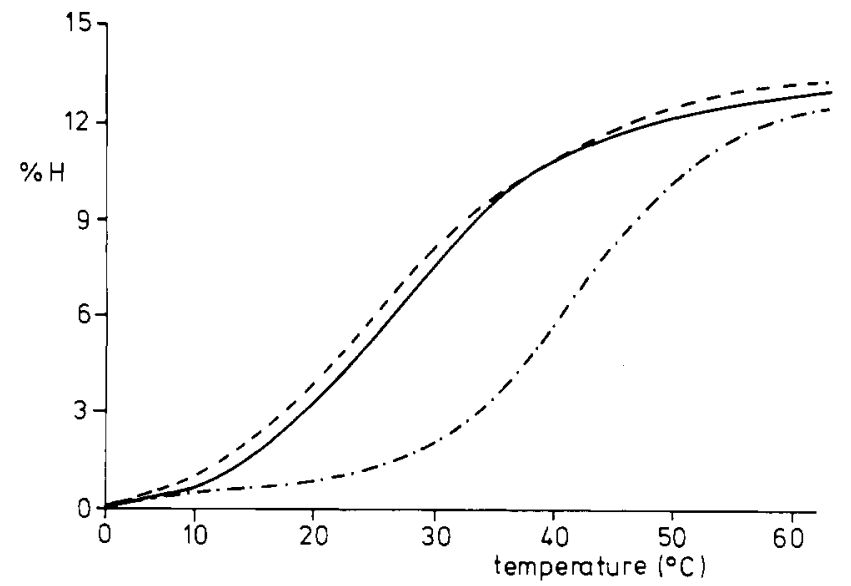

Figure 1. Melting profiles of dsNONA (---), Pt(dien)-dsNONA (-), $\operatorname{Pt}\left(\mathrm{NH}_{3}\right)_{3}$-ds $\mathrm{NONA}(--)$ at $260 \mathrm{~nm}, 4-5 \mu \mathrm{M}$ nonamer strand, $0.5 \mathrm{M}$ $\mathrm{NaCl}, \mathrm{pH} 7$, temperature progression $1{ }^{\circ} \mathrm{C} / \mathrm{min}, \% \mathrm{H}=$ \%hyperchroism.

Therefore, we have investigated the double-stranded nonamer d(TCTCGTCTC).d(GAGACGAGA) modified with the monodentate complexes $[\mathrm{PtCl}($ dien $)] \mathrm{Cl}$ and $\left[\mathrm{PtCl}\left(\mathrm{NH}_{3}\right)_{3}\right] \mathrm{Cl}$, which are bourd to the central guanine base.

In contrast with the results of others, ${ }^{11,12}$ our experiments show that the $T_{\mathrm{m}}$ of the studied nonamer is significantly decreased upon monofunctional platinum binding. This is indicative for a destabilization of the double helix.

The nonamers d(TCTCGTCTC) and d(GAGACGAGA) were synthesized via an improved phosphotriester method. ${ }^{13}$ Pt. (dien)[d(TCTCGTCTC)- $\underline{\mathrm{N}} 7(5)]$ and $\mathrm{Pt}\left(\mathrm{NH}_{3}\right)_{3}[\mathrm{~d}$ (TCTCGTCTC)-N7(5)] were obtained after an equimolar reaction of the platinum compound with the nonamer. The reaction products were identified by NMR. After addition of the complementary strand a duplex is formed; 'H NMR shows that all imino protons are present, even the proton of the platinated G.C base pair (data not shown).

The melting behavior of the two Pt-containing fragments and the unmodified compound were studied. The experimental setup has been described previously. ${ }^{14}$

Under low salt conditions, above $2{ }^{\circ} \mathrm{C}$, the melting profiles of the $\mathrm{Pt}$ nonamers could not be observed completely. Therefore, $\mathrm{NaCl}$ was added to stabilize the duplexes. Figure I shows the melting profiles of the oligonucleotides under comparable conditions. The $T_{\mathrm{m}}$ of the unmodified nonamer is $42^{\circ} \mathrm{C}$. Platination of the fragment with $[\mathrm{Pt}(\text { dien })]^{2+}$ or $\left[\mathrm{Pt}\left(\mathrm{NH}_{3}\right)_{3}\right]^{2+}$ reduces the melting temperature to $26^{\circ} \mathrm{C} .15$

Although several authors predicted a destabilization of the DNA duplex due to fixation of monodentate platinum, ${ }^{16}$ such a drastic

(11) Brabec, V.; Vrâna, O.; Klẹnwächter, V.: Kiss, F. Stud. Biophys. 1984 $101,135-139$

(12) Butour. J. L.; Macquet, J. P. Biochim. Biophys. Acta 1981, 653 $305-315$

(13) van der Marel, G. A.; van Boeckel, C. A. A.; Wille, G.; van Boom, J. H. Nucleic Acids Res 1982,10,2337-2351.

(14) van Houte, L. P. A.; Westra, J. G.; Retèl, J.: van Grondelle, R. Carcinogenesis 1988, 9, 1017-1027.

(15) In a temperature dependence study of the imino protons the difference in melting temperature between the platinated and the unbound noname appears to be the same as observed in the UV melting profiles. decrease in $T_{\mathrm{m}}$ has not yet been reported. Hermann et al. 16a explained the stabilization of the poly(I)-poly(C) duplex after $[\mathrm{Pt}(\mathrm{dien})]^{2+}$ binding with a triple-sandwich structure, i.e., the hypoxanthine- $\mathrm{N} 7$ atoms above and below the one to which $\mathrm{Pt}$ (dien) is bound form hydrogen bonds with protons of the two amino groups of the Pt(dien) moiety. The formation of such a triple-sandwich structure is neighbor dependent and is not likely to occur in our nonamer sequence. These authors also investigated the monofunctional interaction of trans $-\mathrm{PtCl}_{2}\left(\mathrm{NH}_{3}\right)_{2}$ (tDDP) with poly(I)-poly(C).17.18 In agreement with our results, a destabilization of the duplex was found: ${ }^{18}$ the $T_{\mathrm{m}}$ was lowered significantly after $t D D P$ binding. The observation that $[\mathrm{PtCl}($ dien $)] \mathrm{Cl}$ facilitates the $B \rightarrow Z$ transition in poly $(\mathrm{dG}-\mathrm{dC}) \cdot \operatorname{poly}(\mathrm{dG}-\mathrm{dC})^{19,20}$ is another indication that the DVA structure can be significantly affected by monodentate platination.

For oligonucleotides ( $8-10$ base pairs) modified with cDDP a reduction in the melting temperature of $9-27^{\circ} \mathrm{C}$ has been reported 7.8 .21 .22 (Table I). Nevertheless, all imino protons of these duplexes are observed with ' $\mathrm{H}$ NMR.

The melting temperature appears to be dependent on the number of base pairs involved in duplex formation and the location of the platination site (compare $T_{m}$ and $\Delta T_{m}$ of duplex $\Lambda$ and $\mathrm{B}$, Table I). The base sequence of the fragment is also important. This is demonstrated by duplex $B$ and $C$, which are both decamers with the platination site in the middle of the sequence. However. the reduction of the $T_{\mathrm{m}}$ of these decamers is very different. namely 9 and $15^{\circ} \mathrm{C}$, respectively.

In comparison to duplex $C$ our nonamer lacks a guanine-cytosine base pait in the center. For this fragment we measured a $T_{\mathrm{m}}$ lowering of $16^{\circ} \mathrm{C}$ due to monofunctional platinum binding. which compares quite well to a reduction of $15-22^{\circ} \mathrm{C}$ die to bifunctional platination of the related $C$ duplex.

Although the results collected in Table l were obtained under different conditions it is obvious that the reduction of the $T_{\mathrm{m}}$ due to both bifunctional and monofunctional platinum binding is in the same order of magnitude. This result is unexpected in the light of earlier observations. ${ }^{23-25}$ Binding of $[\mathrm{PtCl}(\mathrm{dien})] \mathrm{Cl}$ to random sequence D. $A$ hardly influences the CD spectrum, and the change of the CD induced by bifunctional binding of CDDP is mainly due to the chelation step. ${ }^{23.24}$ Moreover. $[\mathrm{PtCl}(\text { dien })]^{+}$ does not disrupt the duplex of calf thymus DNA in contrast to the effects of CDDP and IDDP. 25

In conclusion, binding of a monofunctional platinum compound distorts the DNA structure significantly. The decrease in melting

(16) (a) Hermann D : Fazakerley G V : Guschlbauer, W Biopolymers $1984,23,973-983$ (b) Johnson, $N$ P. Macquet, J-P. Wiebers, J. L. Monsartat. B. Nucleic Acids Res. 1982, 10, 5255-5271.

(17) Fazakerley, G. V.: Hermann, D.: Guschlbauer. W.: Hawkes, G. E. Biopolymers 1984, 23, 961-972

(18) Hermann. D.: Fazakerley, G. V.: Houssier, C.; Guschlbauer, W Biopolymers $1984,23,945-960$

(19) Malfoy. B.: Hartmann, B.: Leng, M. Nucleic Acids Res. 1981. 9. $5659-5669$.

(20) Ushay, H. M: Santella, R. M. Caradonnu, J. P.: Grunberger. D: Lippard, S. J. Nucleic Acids Res. 1982, 10, 3573-3588.

(21) van Hemelryck, B.; Guittet, E.; Chottard, G.; Girault, J.-P.: Hermann, F.: Huynh-Dinh, T.: Lallemand. J.-Y.: Igolen, J.: Chottard, J.C. Biochem. Biophys. Res. Commun. 1986, 138,758-763.

(22) Marzilli, L. G. $\mathbf{1 9 8 8}$, personal communication

(23) Macquet. J.-P.: Butour, J.-L. Eur. J. Biochem. 1978, 83, 375-387.

(24) Schaller, W.: Reisner. H.: Holler, E. Biochemistry 1987, 26, 943-950.

(25) Sundquist. W. I.: Lippard. S. J. Biochemistry 1986, 25, 1520-1524. 
temperature appears to be almost the same for mono- and bifunctional $\mathrm{Pt}$ compounds. Already in the first platination step the duplex is destabilized, whereafter chelation can take place to form a "kinked" structure, apparently without further major helix destabilization. The details of the helix distortion studied with $C D$ and NMR is the subject of future investigations.

Acknowledgment. We acknowledge EEC support (Grant No. ST2J-0462-C), allowing regular scientific exchange with the group of Prof. Dr J.-C. Chottard, and Johnson and Matthey Ltd. (Reading, UK) for their loan of $\mathrm{K}_{2} \mathrm{PtCl}_{4}$.

\section{Elaboration of Fused gem-Dimethylcyclopropane Systems via Cyclopropene Cycloaddition. A Stereocomplementary Approach}

\section{James H. Rigby* and Paul Ch. Kierkus}

Department of Chemistry, Wayne State University Detroit, Michigan 48202

Received February 10, 1989

A gem-dimethylcyclopropane unit fused to a six-membered carbocycle is a commonly displayed architectural feature characteristic of natural products as structurally diverse as the tumor-promoting diterpene, phorbol (1), ${ }^{1}$ and the sesquiterpene, aristolone (2). ${ }^{2}$

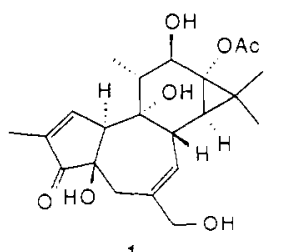

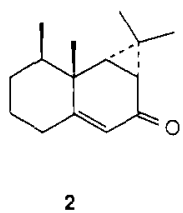

To date, access into the bicyclo[4.1.0]heptane carbon skeleton has most often employed dihalocarbene insertion-organocopper substitution technology, which often provides the target in only modest overall yields. ${ }^{3,4}$ We wish to report a highly stereoselective, general protocol based on cyclopropene cycloaddition chemistry as an alternative method for the elaboration of fused gem-dimethylcyclopropane species. A noteworthy aspect of this methodology is the capability of assembling systems with complementary stereoselection by minor reaction sequence modification.

While several substituted cyclopropene species have displayed dienophilic behavior in simple systems, ${ }^{5}$ gem-dimethylcyclopropene itself is a notoriously poor participant in the Diels-Alder reaction. ${ }^{6}$ We were, however, intrigued with the notion of exploiting the cycloaddition chemistry of the carbonyl-activated dimethylcyclopropene series as an attractive entry into the $C D$ rings of phorbol (1) and related diterpenes.

(1) For synthetic studies on the phorbol system, see: Wender, P. A.; Keenan, R. M.; Lee, H. Y.J. Am. Chem. Soc. 1987, 109, 4390 and references cited therein.

(2) For recent synthetic studies on aristolone, see: Prasad, C. V. C.; Chan, T. H. J. Org. Chem. 1987, 52, 120 and references eited therein.

(3) (a) Taylor, M. D.; Minaskanian, G.; Winzenberg, K. N.; Santone, P.; Smith, A. B. J. Org. Chem. 1982, 47, 3960. (b) Marshall, J, A.; Ruth, J. A. lbid. 1974, 39, 1971 .

(4) Higher order cuprates can provide some improvement in the alkylation step: Harayama, T.; Fukushi, H.; Ogawa, K.; Yoneda, I. Chem. Pharm. Bull. $1985,33,3564$.

(5) For examples of other gem-disubstituted cyclopropenes as dienophiles, see: (a) Apeloig, Y., Arad, D.; Kapon, M.; Wallerstein, M. Tetrahedron Lett. 1987, 28,5917. (b) Boger, D. L.; Brotherton, C. E. Tetrahedron 1986, 42, 2777. For previous studies on the cycloaddition of carbonyl activated gemdimethylcyclopropenes and pyrazoles, see: (c) Dietrich-Buchecker, C; Martina, D.; Franck-Neumann, M. J. Chem. Res. (S) 1978, 78; J. Chem. Res. (M) 1978, 1014. (d) Huisgen, R.; Reissig, H.-U. J. Chem. Soc., Chem. Commun. 1979, 568. (e) Huisgen, R.; Reissig, H.-U. Angew. Chem., Int. Ed. Engl. 1979, 18, 330 3796 .

(6) Closs, G. L.; Closs, L. E.; Boell, W. A. J. Am. Chem. Soc. 1963, 85,
Table I. Cycloadditions of Cyclopropane and Pyrazole Addends with Dienes

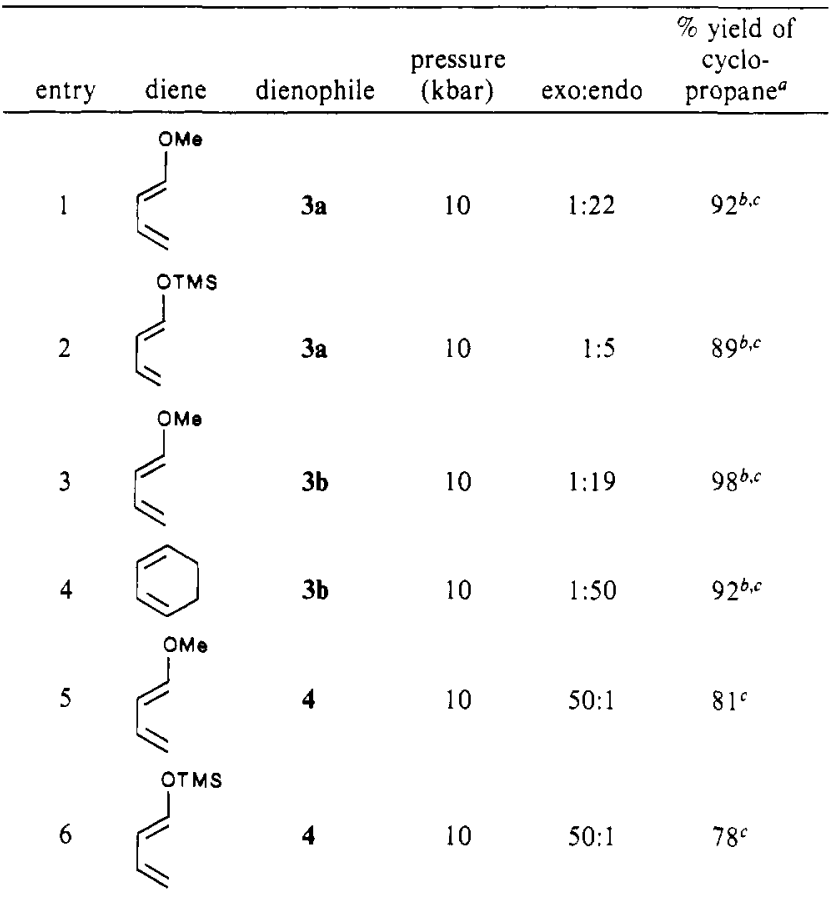

${ }^{a}$ All new compounds reported herein exhibited satisfactory spectral (IR, ${ }^{1} \mathrm{H}$ NMR, ${ }^{13} \mathrm{C}$ NMR), analytical, and/or high resolution mass spectral characteristics. ${ }^{b}$ Overall yield for cycloaddition and quantitative photochemical nitrogen extrusion. "Yield of isolated, purified products.

The requisite addends $\mathbf{3 a}, \mathbf{b}$ and $\mathbf{4}$ were readily prepared by cycloaddition of 2-diazopropane to the appropriately functionalized acetylenes followed, in the case of 4 , by photochemically induced nitrogen extrusion.? Typically, thermal cycloaddition reactions $\left(\mathrm{CH}_{2} \mathrm{Cl}_{2}, 50^{\circ} \mathrm{C}, 96 \mathrm{~h}\right)$ of these reagents required massive excesses of diene to assure adequate yields of adducts. However, performing the additions at high pressure $\left(\mathrm{CH}_{2} \mathrm{Cl}_{2}, 8-10 \mathrm{kbar}, 18\right.$ h) provided excellent yields of products employing essentially $1: 1$ diene-dienophile stoichiometry. The results of the reaction of $3 \mathrm{a}$ and 4 with $(E)$-1-acetoxy-1,3-butadiene are illustrative.

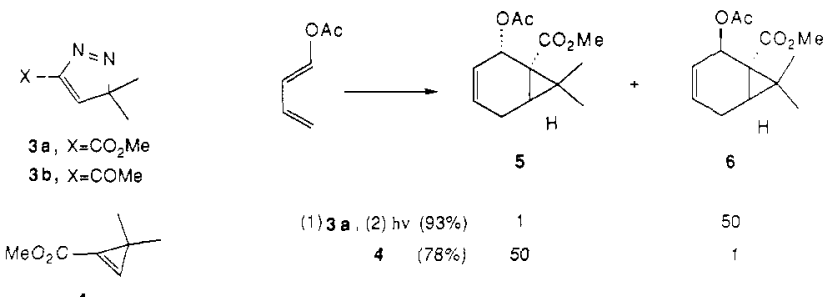

Exposure of this diene to cyclopropene $4\left(\mathrm{CH}_{2} \mathrm{Cl}_{2}, 10 \mathrm{kbar}, 18\right.$ h) provided adducts 5 (exo) and 6 (endo) in $78 \%$ yield with an exo:endo ratio of $50: 1^{8,9}$ paralleling the established proclivity for exo addition exhibited by hindered cyclopropenes. ${ }^{\text {sa }}$ In marked contrast, pyrazole 3a gave, after cycloaddition $\left(\mathrm{CH}_{2} \mathrm{Cl}_{2}, 10 \mathrm{kbar}\right.$, $18 \mathrm{~h})$ and quantitative photochemical nitrogen extrusion (3500 $\AA, 2.5 \mathrm{~h}$ ) from the bicyclic pyrazoline intermediate, a $93 \%$ overall yield of a mixture of 5 and 6 in which the endo diastereomer 6 prevailed in a ratio of 50:1. ${ }^{10}$ Thus, effective complementary

(7) Padwa, A 1,3-Dipolar Cycloaddition Chemistry; John Wiley \& Sons New York, 1987; Vol. 1, pp 393-558. The photochemistry of $\mathbf{3 b}$ was not well-behaved, and the corresponding cyclopropene was not readily available for cycloaddition studies: Dietrich-Buchecker, C.; Franck-Neumann, M. Tetrahedron 1977, 33, 751.

(8) The exo/endo designation is relative to the gem-dimethylcyclopropane moiety.

(9) The corresponding $Z$-dienes do not react to any appreciable extent under these conditions as evidenced by the total absence of reactivity of (Z)-1-acetoxy-1,3-butadiene toward 3a and 4 . 